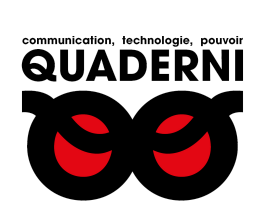

\title{
Quaderni
}

Communication, technologies, pouvoir

104 | Automne 2021

Colères politiques

\section{Une si saine colère}

\section{Emmanuel Täieb et Étienne Candel}

\section{(2) OpenEdition \\ Journals}

Édition électronique

URL : https://journals.openedition.org/quaderni/2093

DOI : 10.4000/quaderni.2093

ISSN : 2105-2956

Éditeur

Les éditions de la Maison des sciences de l'Homme

Édition imprimée

Date de publication : 15 octobre 2021

Pagination : 5-8

Référence électronique

Emmanuel Täieb et Étienne Candel, « Une si saine colère », Quaderni [En ligne], 104 | Automne 2021, mis en ligne le 15 octobre 2021, consulté le 08 novembre 2021. URL : http://journals.openedition.org/ quaderni/2093 ; DOI : https://doi.org/10.4000/quaderni.2093 


\section{Éditorial: \\ Une si saine colère}

\section{Emmanuel Taïeb}

Sciences Po Lyon (Triangle)

\section{Étienne Candel}

Université de Paris (CERLIS) 
"La peur est le chemin vers le côté obscur : la peur

mène à la colère, la colère mène à la haine,

la haine mène à la souffrance"

Maître Yoda

Découvrir ou redécouvrir le potentiel des émotions politiques à devenir un chantier de recherche pour les sciences sociales implique de se défaire de plusieurs idées un peu rebattues. Non qu'elles soient intrinsèquement fausses, mais l'épreuve des faits les a passablement rendues archaïques. Ainsi, le "peuple" n'est pas la seule entité à ressentir des émotions - qui le feraient alternativement se mettre en grève, arpenter le pavé ou invectiver ses élus -, les hommes et les femmes politiques ne sont pas des animaux à sang froid qui ne ressentiraient rien ou feraient mine d'être dans une pure rationalité n'accordant aucun espace visible aux affects, et la distinction entre des émotions "positives" ou "négatives" est purement normative. La "saine colère" de Ségolène Royal lors de son débat de second tour avec Nicolas Sarkozy en 2007 est là pour le rappeler. De fait et par exemple, c'est bien la colère froide, autant que l'empathie, qui peut pousser à l'engagement humanitaire ou politique. C'est bien le sentiment d'injustice qui noue le ventre et pousse à l'action. C'est le ressentiment qui alimente les populismes. C'est aussi sur la peur que jouent divers partis politiques, de l'extrême droite qui fantasme l'invasion et la dépossession économique ou raciale depuis plus d'un siècle, à une certaine écologie politique qui axe son discours sur la perspective de la fin du monde et le réveil des consciences (voir Quaderni ${ }^{\circ}{ }^{102}$ ).

Rien de "négatif" en définitive, si ce n'est que ces émotions ne sont pas toujours agréables à ressentir ou à exprimer, et qu'elles peuvent être surtout historiquement et socialement délégitimées (la colère est l'un des sept péchés capitaux dans le christianisme et elle était décrite comme une passion chez les Grecs). D'où leur faible emploi dans l'arène médiatico-politique, quand l'injonction à la maîtrise de soi des élus est dominante. La colère politique dit le relâchement de ce contrôle, et inquiète à ce titre. Elle reste discrète, visible dans les fictions, ou enfermée derrière les murs des lieux de pouvoir, "recadrage" présidentiel de ministres ou coup de sang en réaction à une information, par exemple, devenant parfois une indiscrétion dans la presse'. À l'inverse, lorsque Jacques Chirac ou Emmanuel Macron s'emportent contre les services de sécurité israéliens, c'est dans une tentative d'incarnation de la puissance du pays à destination de ses témoins à l'international. Le reste du temps, dans une démocratie légale-rationnelle, l'autocontrôle des politiques est l'héritier des qualités de retenue et de sagesse prêtées au Prince depuis la Renaissance. Machiavel, pourtant, a ouvert d'autres perspectives, celles de l'animalité du prince, de

1. Charlotte Chafanjon, "La colère de Macron face à ses ministres, une menace à peine voilée avant 2022 ", Libération (en ligne), 25/06/2021. 
sa cruauté, mais également de la "fureur" de la fortune ou de celle du peuple à qui on vole sa liberté2. C'est cette autre ligne, moins explorée, qui semble se réactiver aujourd'hui. Celle qui fait dire à la psychologie que la colère survient quand les choses ne paraissent pas à leur place. Elle est un mouvement passionnel de retour à un état antérieur et participe en fait de l'engagement social et politique comme de la construction de soi.

Les dernières recherches en sciences sociales montrent, elles, que le rôle et les usages des émotions méritent une attention renouvelée. Les fluctuations somatiques - affects forts et dégoût - ont été analysées comme révélant des inquiétudes et des peurs sociales, nouant dans le corps même le physique et le social ${ }^{3}$. En politique, dans le cas du pouvoir municipal, Alain Faure a par exemple montré que, de l'Italie au Japon, le jeu des émotions, voire le désir simple d'être aimé, déterminent la volonté d'être maire et d'aider ses concitoyens ${ }^{4}$. Christian Le Bart $a$, lui, mis en évidence un usage stratégique des émotions politiques, y compris des plus taboues habituellement (tristesse, choc, colère justement), qui signe en pratique leur présence publique de plus en plus marquée 5 .

À ce titre, non seulement les émotions relèvent pleinement des sciences anthropo-sociales, mais encore doivent-elles s'aventurer, comme le fait le dossier de ce numéro, dans leurs dimensions les plus méconnues. À la fois pour lever le voile sur les mécanismes contribuant à disqualifier la colère politique comme ses émotions voisines (l'indignation, la hargne, l'offense désormais), et pour montrer à quel point elles s'établissent en ressorts de l'action politique contemporaine. L'indignation règne par exemple sur les réseaux sociaux, comme mode dominant du rapport au monde. Chaque jour l'exposition d'une turpitude appelle la colère et désigne un coupable... jusqu'à l'indignation du lendemain. La construction du scandale est permanente. À croire que la saine colère du citoyen est une humeur passagère, mais qui s'entretient longtemps.

Si les émotions médiatisent le lien à l'univers social, il ne faut pas négliger ce que provoque politiquement le sentiment de mépris, d'injustice ou de discrimination: ainsi parfois dans un jeu à plusieurs bandes, la dénégation même d'un sentiment (au hasard, le sentiment d'insécurité des années 2000) en génère un autre encore plus violent (la haine d'élites déconnectées du réel). Dans un jeu en miroir aussi, les colères peuvent en venir à structurer des pratiques et des visions du monde opposées: colère contre ce que l'écriture inclusive fait à la langue et colère opposée lorsqu'elle n'est pas utilisée, colère quand les politiques agissent et colère lorsqu'ils sont

2. Discours sur la première décade de Tite-Live (ch. XXII).

3. Dominique Memmi, Gilles Raveneau et Emmanuel Taïeb (dir.), Le social à l'épreuve du dégoût, Rennes, PUR, 2016.

4. Alain Faure, Des élus sur le divan. Les passions cachées du pouvoir local, Grenoble, PUG, 2016.

5. Christian Le Bart, Les Émotions du pouvoir. Larmes, rires, colères des politiques, Paris, Armand Colin, 2018. 
apathiques. Trump était un homme en colère, contre les tenants du changement climatique et les représentants de l'establishment. Son pendant brésilien, Jair Bolsonaro, a mis son peuple en colère pour son attitude de déni et sa gestion hasardeuse face à la crise sanitaire. On voit là à quel point les principes de l'économie morale d'E.P.Thomson valent aussi pour d'autres secteurs du monde social. Avec le risque cependant d'agréger et d'écraser des affects bien différents sous le terme unique de colère, qui signe souvent l'échec de mouvements plus oppositionnels que proactifs.

La république "tumultueuse" qu'appelait de ses vœux Machiavel, encore, est bien celle qui accepte les nécessaires passions humaines, les valorise et les norme, mais les met surtout à égalité. Tout ce qui relève de la discussion politique, aujourd'hui dans ses bornes démocratiques, est acceptable, et sous cet aspect, comme le rappelle Thierry Devars dans son avant-propos, la colère peut s'apparenter à une "passion raisonnable". Elle irrigue en tout cas la communication des hommes et femmes politiques, leur nouvelle manière d'apparaître comme des êtres traversés par les émotions, et irrigue également des mobilisations très différentes, des complotistes de QAnon au mouvement Black Lives Matter. Reste à savoir à quel moment la colère peut se transformer en souffrance, et retourner du politique, du social et du collectif vers le moral, l'individuel et le psychologique. 